\title{
Questões de gênero e sexualidade na educação brasileira
}

O presente estudo, em tela ou em mãos, tem como objetivo: apresentar e discutir como as questões de gênero e sexualidade perpassam a educação brasileira. Metodologicamente, possui uma abordagem qualitativa, em nível exploratório, de tipo bibliográfico. Destaca-se que autores/as como Guacira Lopes Louro, Judith Butler, Miguel Arroyo são apresentados no desenvolvimento da discussão. Pode-se considerar a partir do estudo que os processos educacionais (formais e informais) são atravessados por uma norma que toma como base a heterossexualidade como norteadora, e que as escola e universidades constituem-se como espaços de violência (física e simbólica) onde as pessoas LGBTQI+ podem ser alvos de homofobia por conta de suas vivências no âmbito da sexualidade.

Palavras-chave: Educação; Gênero e Sexualidade; Escola; Universidade; Brasil.

\section{Gender and sexuality issues in Brazilian education}

The present study, on screen or in hands, aims to: present and discuss how gender and sexuality issues permeate Brazilian education. Methodologically, it has a qualitative approach, on an exploratory level, of a bibliographic type. It is noteworthy that authors such as Guacira Lopes Louro, Judith Butler, Miguel Arroyo are presented in the development of the discussion. It can be considered from the study that the educational processes (formal and informal) are crossed by a norm that takes heterosexuality as a guideline, and that schools and universities are spaces of violence (physical and symbolic) where LGBTQI+ people can be targets of homophobia because of their experiences in the area of sexuality.

Keywords: Education; Gender and Sexuality; School; University; Brazil.

Topic: Cultura, Gênero e Subjetividade

Reviewed anonymously in the process of blind peer.
Received: 24/10/2020

Approved: 25/01/2021
Antoniel dos Santos Gomes Filho

Centro Universitário Vale do Salgado, Brasil

http://lattes.cnpq.br/9563145614494252

http://orcid.org/0000-0003-2230-4315

antoniel.historiacomparada@gmail.com

\section{Lielton Maia Silva (iD)}

Centro Universitário Vale do Salgado, Brasil

http://lattes.cnpq.br/8591384775803008

http://orcid.org/0000-0002-5126-8205

lieltonmaia@univs.edu.br
Referencing this:

GOMES FILHO, A. S.; SILVA, L. M.. Questões de gênero e sexualidade na educação brasileira. Educationis, v.9, n.1, p.8-16, 2021. DOI: http://doi.org/10.6008/CBPC2318-3047.2021.001.0002 


\section{INTRODUÇÃO}

Compreendendo que as bases da sociedade brasileira, estão arraigadas nos processos de colonização e invasão dos povos europeus nas américas, que tomaram a figura do homem branco e europeu como referência, para pensar os corpos e as possibilidades de existência social, faz-se necessário um novo movimento, onde a educação, é um dos lugares para re-pensar as questões de gênero e sexualidade em nosso território, em especial nas relações desenvolvidas nas escolas e universidades ${ }^{1}$.

A filósofa italiana Braidotti (2000) nos lembra que os movimento do pensamento nômade, inserido nas teorias feministas contemporâneas "vaya allá de las imposiciones conceptuales dualistas y los hábitos perversamente monológicos del falocentrismo", assim, diante dos movimentos e mudanças sociais em relação as visibilidades das diversidades de gênero e sexual conquistadas através dos movimentos e ativismos sociais, podemos na atualidade buscar romper com conceituações de pensamento de ordem dualistas, que atingem as pessoas que não seguem as regulações sociais para os corpos, o gênero e a sexualidade, nessa ordem dual (GOMES FILHO, 2017a).

Destaca-se que os movimentos e lutas sociais, que se fortaleceram a partir dos anos de 1970, com os primeiros movimentos gays e lésbicos, hoje denominado, no caso brasileiro, como LGBTQI+, foram e são responsáveis pela entrada das questões de gênero e sexualidade no espaço público, e também nos espaços escolares e universitários, em específico nas primeiras décadas do século XXI, porém como aponta Arroyo (2017) esses outros sujeitos não estão inseridos historicamente nos processos pedagógicos tradicionais, sendo necessário assim a produção de outras pedagogias que resistam e façam emergir os saberes desses outros sujeitos, logo, é necessário construir outros currículos.

A formação profissional na contemporaneidade não pode deixar de abarcar os debates que envolve as questões de gênero e sexualidade, uma vez que estes futuros profissionais podem em seu cotidiano de trabalho deparar-se com uma pessoa LGBTQI+ (ou ele mesmo ser), que tem demandas psicossociais especificas, até, um caso grave de violência física, como é visto rotineiramente nos mais diversos pontos do Brasil. Nesse sentido, Villela et al. (2017) a categoria gênero tem sido incorporada no ensino de saúde e nos mais diversos campos do saber.

Assim, diante das questões expostas, o presente estudo é norteado pela seguinte questão problema: quais são as questões de gênero e sexualidade que perpassam a educação brasileira na contemporaneidade? Logo, o objetivo principal do estudo consiste em apresentar e discutir como as questões de gênero e sexualidade perpassam a educação brasileira.

A investigação, metodologicamente, apoia-se numa abordagem qualitativa, pois como aponta Flick (2009b; 2009a), esta abordagem trata de modo mais particular a "pluralização" das diversas esferas da vida, tanto individual como social. A abordagem qualitativa no curso histórico das pesquisas no feminismo e nos estudos de gênero e sexualidade vê, nessa abordagem, uma forma de dar voz aos indivíduos historicamente silenciados. Gamson (2006) aponta que o enfoque qualitativo tem uma preocupação com a pesquisa e a

${ }^{1} \mathrm{O}$ termo é aqui utilizado para abarcar todas as Instituição educacionais que ofertam o Ensino Superior. 
política da sexualidade, que se torna um desafio aos investigadores na atualidade, já que no curso histórico dos próprios estudos há múltiplos olhares sobre o fenômeno do gênero e da sexualidade.

Porém, independente do ponto de vista que se observe, de modo geral, segundo Gamson (2006) as pesquisas qualitativas em gênero e sexualidade possuem:

[...] elementos que são familiares àqueles encontrados nas histórias sobre os estudos das mulheres [...] é uma história que se entrelaça com a política dos movimentos sociais, assim, junto com os movimentos sociais as pesquisas qualitativas buscaram dar mais espaços às vozes e às experiências que foram suprimidas. (GAMSON, 2006)

O tipo de pesquisa é bibliográfico, que de acordo com Marconi et al. (2017) "é um tipo de produção científica que é feita com base em textos, como livros, artigos científicos [...]". As pesquisadoras apontam que na atualidade há um foco nos artigos científicos como fonte primeira para os estudos bibliográficos, já que estes apresentam o que há de mais recente no conhecimento científico. Desse modo, o estudo é de nível exploratório, que de acordo com Gil (2009) "têm como principal finalidade desenvolver, esclarecer e modificar conceitos e ideias, tendo em vista a formulação de problemas mais precisos ou hipóteses pesquisáveis para estudos posteriores". A seleção dos livros e artigos (HOHENDORFF, 2014) deu-se nas seguintes bases de dados: Google Acadêmico e Books, Scientific Electronic Library Online (SciELO), juntamente com livros considerados basilares para os estudos de gênero e sexualidade no pais, a exemplo: O corpo educado: pedagogias da sexualidade (2000), Gênero, sexualidade e educação: uma perspectiva pósestruturalista (2003) de Guacira Lopes Louro; Problemas de gênero: feminismo e subversão da identidade (2008) de Judith Butler; Outros sujeitos, outras pedagogias (2017) de Miguel Arroyo.

Aponta-se que a pesquisa se justifica frente a emergência dos debates sobre gênero e sexualidade nos espaços universitários, pois, como aponta Quirino (2017) é "urgente a recuperação de práticas de cuidado nas quais os profissionais tenham interesse e valorizem as pessoas de forma ética, e assumindo uma atitude de responsabilidade social, embasadas no desejo de cuidar [...]".

\section{DISCUSSÃO TEÓRICA}

\section{Questões de gênero e sexualidade na educação brasileira}

Os processos educacionais formais e informais são atravessados por comportamentos, valores e ideais que, sócio-historicamente, priorizam a binaridade do sexo e gênero (masculino e feminino) e a heterossexualidade, como uma construção de sexualidade normatizada. Tais interpelações atravessam o processo de ensino-aprendizagem nas escolas e universidades. As instituições educacionais são locais onde as "pedagogias da sexualidade" (LOURO, 2000) são solicitadas a todo o momento para ensinar aos corpos, como estes devem ser ou estar no mundo, tendo como referência as genitálias, como partes do corpo que "organizam" o curso inteligível da vida social e sexual (BUTLER, 2008).

Os conceitos de sexo, gênero e sexualidade desde meados do século XX vêm sendo (re)criados e disputados por diversos campos do saber, como: as ciências médicas e biológicas, e as ciências humanas e sociais (história, filosofia, sociologia, educação, etc.) (GOMES FILHO et al., 2017). Diante dessas disputas em torno dos conceitos de gênero e sexualidade, apresenta-se os olhares interdisciplinares da vertente sócio- 
histórica, que, compreendem que tais categorias são criadas e recriadas ao longo da vida e do cotidiano dos sujeitos, fazendo parte de suas subjetividades, que são atravessadas por diversos marcadores individuais e coletivos, que são organizados no tempo e no espaço social (BUTLER, 2000; 2008; BENTO, 2006; 2009; LOURO, 2000; 2003).

De acordo com Weeks (2000) a sexualidade está correlacionada "[...] como uma descrição geral para a série de crenças, comportamentos, relações e identidades socialmente construídas e historicamente modeladas [...]". Desse modo, como afirmam Gomes Filho et al. (2017) a sexualidade consiste em uma "mistura" das mais diversas instâncias corporais, com seus usos e práticas no campo individual e coletivo. Furlani (2009) nos lembra que o fenômeno da sexualidade está agregado a um conhecimento temporal, circunstancial e contingencial. Assim, as sociedades podem legitimar ou condenar práticas e desejos sexuais, assim, o saber em torno da sexualidade é uma construção humana, que envolve discutas e relações de poder, as instituições sociais que compõe a sociedade, consolidando assim alguns discursos normativos, que inserem algumas pessoas, "o outro", em desigualdade social.

Os processos sociais e históricos da construção do gênero e da sexualidade na sociedade é atravessado pela manutenção dos ideais heterossexuais, que adentram os espaços escolares e universitários, com seus processos de regulação e normatização para os corpos e as práticas sexuais, de várias maneiras, inclusive no currículo. Segundo Furlani (2009):

Na expectativa social da sexualidade, há uma "obrigatória" e inquestionável associação entre sexo biológico + orientação sexual + prática sexual + identidade de gênero que se traduz numa lógica onde mulheres e homens devem corresponder aos seguintes modelos: mulher-heterossexual-passiva-feminina; enquanto o homem-heterossexual-ativomasculino. (FURLANI, 2009)

No campo educacional, aponta Louro (2000), a escola é um dos locais onde se aprende as normas sociais construídas para o masculino e o feminino, incorporadas nos corpos que possuem biologicamente um pênis ou vaginas, sendo "[...] a heterossexualidade concebida como 'natural' e também como 'universal e normal'”. Assim, indivíduos que não se adequem as normas sociais estão passiveis de vigilância, punição e exclusão, social e educacional.

Segundo Turner (1999) o espaço escolar e universitário são lugares de socialização, onde "cada um de nós deve ser guiado interiormente por símbolos culturais comuns - o que podemos chamar de diretrizes culturais". Gomes Filho (2017a; 2017b) destaca que as construções culturais para a sexualidade no contexto brasileiro são atravessadas por uma representação social que aloca homens e mulheres em determinados espaços, que acabam por criar uma ideia de naturalidade dessas construções sociais para os gêneros, sendo estas representações compartilhadas de alguma forma nas interações e socializações educacionais.

Estudos mostram (JALÓN, 2006; ASSIS et al., 2010; QUARESMA, 2010; BENTO, 2011) que a escola e a universidade são espaços de violência e não se constituem como lugares de acolhimento à multiplicidade dos desejos sexuais, das orientações sexuais e identidades de gênero, mesmo que este espaço, seja um local multicultural. Desta forma, os espaços educacionais "formais" podem transforma-se em um lugar de repressão social e da liberdade de expressão, seja ela de caráter físico ou social, marginalizando aqueles que fogem dos padrões estabelecidos socialmente, que condiciona a todos a pensar na sociedade de um ponto 
de vista heteronormativo, excluindo e subjugando aqueles que fogem desse padrão.

Contudo, as pessoas que possuem uma orientação sexual e identidade de gênero diferente, e desejam amar e se relacionar com uma pessoa do mesmo sexo acaba passando por um processo de estigmatização perante a comunidade escolar e universitária, processos estes que são caracterizado como homofobia, que pode vir de modo oculto e peculiar ser re-produzida, através de comportamentos preconceituosos, discriminação, ofensas, ameaças, constrangimentos, agressões físicas, verbais e psicológicas, e tem sido cada vez mais frequente na vida escolar, universitária e profissional de jovens e adultos LGBTQI+.

Nas últimas décadas, é crescente o número de pesquisas no campo da educação que buscam compreender as diversas relações existentes dentro do espaço escolar, pelos sujeitos que compõe este lugar tão heterogêneo que é a escola e universidade brasileira. Dentre estes estudos ganham espaço os que têm como objeto de análise a homofobia, haja vista o destaque contemporâneo para esse novo fenômeno social. De acordo com Borrillo (2010):

\begin{abstract}
A homofobia pode ser definida como a hostilidade geral, psicológica e social contra aquelas e aqueles que, supostamente, sentem desejo ou têm práticas sexuais com indivíduos de seu próprio sexo. Forma especifica de sexismo, a homofobia rejeita, igualmente, todos aqueles que não se conformam com o papel predeterminado para seu sexo biológico. Construção ideológica que consiste na promoção constante de uma forma de sexualidade (hétero) em detrimento de outra (homo), a homofobia organiza uma hierarquização das sexualidades e dessa postura, extrai consequências políticas. (BORRILLO, 2010)
\end{abstract}

Assim, muitos/as pesquisadores/as vêm buscando entender como ocorre a homofobia nos ambientes educacionais (LOURO, 2000; JUNQUEIRA, 2009; BENTO, 2011).

Tais preconceitos e discriminações incidem diretamente na constituição de seus perfis sociais, educacionais e econômicos, os quais, por sua vez, serão usados como elementos legitimadores de ulteriores discriminações e violências contra elas. A sua exclusão da escola passa, inclusive, pelo silenciamento curricular em torno delas. (JUNQUEIRA, 2009)

A escola mantém-se como um ambiente de produção de experiências sociais e do conhecimento, mas, quando direciona certa atenção para homossexualidade, é encarada como um espaço de desconhecimento, causando assim uma confusão no que diz respeito ao papel da escola na vida do sujeito (LOURO, 2000). Esse processo é gerador de violências motivadas pelas questões de gênero e sexualidade, tal como aponta Abramovay et al. (2004) em seu relatório de pesquisa:

Quando se pergunta aos alunos sobre quais pessoas ele não gostaria de ter como seu colega de classe, aproximadamente $1 / 4$ dos alunos indicam que não gostariam de ter um colega homossexual, sendo que os percentuais extremos dessas respostas ficam entre $30,6 \%$ (Fortaleza) e 22,6\% (Belém), o que corresponde em números absolutos a 112.477 (Fortaleza) e a 43.127 (Belém). Ressalta-se que os jovens do sexo masculino, em qualquer capital analisada, rechaçam com maior intensidade a homossexualidade. Por exemplo, em Porto Alegre, enquanto $42 \%$ dos rapazes indicam tal preconceito, no caso das moças, baixa para $13 \%$. São mais altas que no caso de alunos, as proporções de pais que mencionam que não gostariam que homossexuais fossem colegas de escola do seu filho. Tal indicador de rejeição está entre 47,5\%, em Fortaleza, e 22,2\%, em Porto Alegre. Corroborando a tendência antes analisada, os homens são mais preconceituosos, chegando, em Recife, a $60 \%$ e, em Fortaleza, a 59,2\%. (ABRAMOVAY et al. 2004)

Então, pode-se inferir que a escola e a universidade não abordam este assunto de forma aberta, e tampouco há uma preocupação em abordar tal temática dentro da constituição de seu currículo, tratando o 
assunto de forma silenciosa e oculta, sem levar em consideração a importância deste currículo para a formação social e profissional. Gomes Filho et al. (2015) destaca que a sexualidade na escola tem um foco "nas Doenças Sexualmente Transmissíveis (DSTs) e nos meios contraceptivos, como se não existissem outras categorias mais urgentes a serem discutidas, como os estereótipos de gênero, o machismo e a homofobia. A questão do prazer e da violência não abordadas". Assim, observa-se que há um enfoque biológico, logo, outros olhares disciplinares (história, sociologia, filosofia) não são solicitados para o debate.

Como bem aponta Santomé (1998), quando se trata de pensar as sexualidades lésbicas e homossexuais, e dos demais dissidentes de gênero e orientação sexual, tende-se a instaurar a cultura LGBTQI+ em construções sociais negativas. Como escreve o sociólogo:

A cultura homossexual e lésbica [LGBT] não é uma questão individual, mas social; é algo relacionado com todo o âmbito das relações humanas, com estruturas sociais e de trabalho. Uma prova disso são as proibições expressas ou latentes que ainda pesam sobre os membros desse grupo para encontrar emprego. Existe também uma tendência à os transformar em bode expiatório de todos os males. Assim, por exemplo, vemos como se tem recorrido aos homossexuais para tratar de explicar a origem de uma praga como a AIDS. Em numerosos meios de comunicação e em múltiplas declarações de especialistas, pessoas com este tipo de sexualidade são apresentadas como se fossem aficionadas às drogas, marginais ou lúmpen. (SANTOMÉ, 1998)

O contexto apresentado nos anos 1990, ainda pode ser considerado atual, pois, as populações LGBTQI+ no Brasil ainda sofrem grandes violações de direitos, inclusive quando se pensa em debater uma cultura que promova a diversidade sexual e de gênero, bem como os conhecimentos oriundos dos movimentos LGBTQI+, no campo do currículo e no cotidiano escolar e universitário, sendo tais pautas intituladas erroneamente de promoção de uma 'doutrinação de ideologia de gênero'.

A sexualidade nos espaços educacionais e no currículo surge como um saber objetivo, pronto e acabado, não existindo espaço para que as diferenças de ideias, pessoas e coisas. Logo, o saber é apresentado como verdade universal comum a todos que se fazem presentes na escola e universidade, nas salas de aula. Estes processos de síntese curricular universal são "estrategicamente formulados de modo que as ideias expressas se não dispersem e as realidades descritas não causem dúvida. Por isso que o objetivo permanece o mesmo - inviabilizar o contraditório, o pensamento livre e desenfreado, o desejo do dissemelhante" (Ó, 2016). Assim, o currículo torna-se um artefato e um dispositivo de produção de violência simbólica quando se torna um meio de silenciamento da diversidade sexual, e quando impossibilita o processo de livre pensamento de temas como a homofobia e a descriminação e estigmatização dos LGBT na sociedade.

Desse modo é necessário pensar a construção do currículo na formação profissional no campo da saúde ${ }^{2}$, pois como pode ser visto, as questões de gênero e sexualidades estão postas na sociedade, sendo debatidas e discutidas em todos os espaços, inclusive os da saúde, pois como aponta Glauberto Quirino:

Durante o processo formativo na saúde e no transcorrer das condutas profissionais, nos deparamos com discussões que contemplam a ética, limites das nossas intervenções, enquanto profissionais integrantes da equipe de saúde e tomada de decisões no cotidiano do trabalho (SANTANA et al., 2012). Diante disso, os profissionais de saúde têm responsabilidade ética e legal em relação ao serviço que é prestado para o usuário dos

\footnotetext{
${ }^{2}$ Esse olhar para a saúde está atravessado pelas experiências dos pesquisadores no que tange os processos de ensino-aprendizagem como docentes em cursos superiores de saúde em IES no interior do Ceará.
} 
serviços de saúde. (QUIRINO, 2017)

Portanto, quando se pensa na formação de profissionais de saúde as questões éticas emergem, e consequentemente as questões morais também devem ser pensadas, atreladas as construções sociais e históricas para os gêneros, uma vez que as normatizações do gênero e da sexualidade é atravessada pelo tempo e cultura.

Assim, a necessidade de apresentar currículos que tratem sobre as temáticas a partir da perspectiva sócio-histórica é importante para que os discentes possam ampliar seus olhares, que muitas vezes estão voltados para as questões técnicas, que em muitos momentos deixam as questões de humanização em outros planos de importância. Por isso, é necessário que se pense outros currículos em gênero e sexualidade para a formação dos profissionais da área da saúde.

\section{CONSCLUSÕES}

Pode-se considerar inicialmente que as questões que envolvem o gênero e a sexualidade na educação brasileira são diversos e múltiplos, tanto qualitativamente, quanto quantitativamente. Sob este ponto, considera-se que o estudo apresentado, em tela ou em mãos, não abarca a totalidade sobre as relações entre os fenômenos educacionais com o gênero e a sexualidade humana.

Através das questões apresentadas no estudo pode-se considerar que: 1. Os processos educacionais (formais e informais) são atravessados por uma norma que toma como base a heterossexualidade como norteadora. Tal norma, gera um processo de estigmatização das pessoas que não se adequam a estas normas construídas social e culturalmente; 2 . As escola e universidades constituem-se como espaços de violência (física e simbólica), onde as pessoas LGBTQI+ podem ser alvos de homofobia por conta de suas vivências no âmbito da sexualidade; 3 . Os currículos escolares tendem a tratar o fenômeno da sexualidade humana como saber biológico (diferenciação e reprodução sexual, DSTs, etc.), não ampliando assim outros olhares sobre esse fenômeno e suas relações com a sociedade, a história e a política; 4. A formação de profissionais em nível superior deve buscar em seus currículos incluir s questões de gênero e sexualidade, a fim de ampliar a formação teórico-prática e ética desses novos profissionais.

Considera-se que o currículo "[...] é considerado como um artefato social e cultura. Isso significa que ele é colocado na moldura mais ampla de sus determinações sociais, de sua história, de sua produção contextual" (MOREIRA et al., 2013), desse modo, sua re-construção está correlacionada as demandas e contingências de um tempo e um espaço. Assim, repensar os currículos, e introduzir as questões de gênero e sexualidade é um debate emergente na sociedade brasileira na contemporaneidade, que é atravessada por diversos olhares e disputas narrativas.

Portanto, ressaltasse que o artigo/texto apresentou e discutiu algumas questões de gênero e sexualidade que perpassam a educação brasileira, logo, outros estudos e pesquisas (teóricas e empíricas) podem surgir como desdobramentos do mesmo, para os pesquisadores leitores deste artigo.

\section{REFERÊNCIAS}


ABRAMOVAY, M.; CASTRO, M. G.; SILVA, L. B.. Juventude e sexualidade. Brasília: UNESCO Brasil, 2004.

ARROYO, M.. Outros sujeitos, outras pedagogias. Petrópolis: Vozes, 2017.

ASSIS, S. G.; CONSTANTINO, P.; AVANCI, J. Q.. Impactos da violência na escola: um diálogo com professores. Rio de Janeiro: FIOCRUZ, 2010.

BENTO, B.. A diferença que faz a diferença: corpo e subjetividade na transexualidade. Revista Bagoas, v.4, p.95112, 2009.

BENTO, B.. A reinvenção do corpo: sexualidades e gênero na experiência transexual. Rio de Janeiro: Garamond, 2006.

BENTO, B.. Na escola se aprende que a diferença faz a diferença. Revista Estudos Feministas, Florianópolis, v.19, n.2, 2011

BORRILLO, D.. Homofobia: história e crítica de um preconceito. Belo Horizonte: Autêntica, 2010.

BRAIDOTTI, R.. Sujetos nómades: corporización y diferencia sexual en la teoria feminista contemporánea. Buenos Aires: Paiós, 2000.

BUTLER, J.. Corpos que pesam: sobre os limites discursivos do sexo. In: LOURO, G. L.. O corpo educado: pedagogias da sexualidade. 2 ed. Belo Horizonte: Autêntica, 2000.

BUTLER, J.. Problemas de gênero: feminismo e subversão da identidade. 2 ed. Rio de Janeiro: Civilização Brasileira, 2008.

FLICK, U.. Desenho da pesquisa qualitativa. Porto Alegre: Artmed, 2009a.

FLICK, U.. Introdução à pesquisa qualitativa. 3 ed. Porto Alegre: Artmed, 2009b.

FURLANI, G.. Mitos e tabus da sexualidade humana. 3 ed. Belo Horizonte: Autêntica, 2009.

GAMSON, J.. As sexualidades, a teoria queer e a pesquisa qualitativa. In: DENZIN, N. K.; LINCOLN, Y. S.. 0 planejamento da pesquisa qualitativa: teorias $\mathrm{e}$ abordagens. Porto Alegre: Artmed, 2006.

GIL, A. C.. Métodos e técnicas de pesquisa social. 6 ed. São Paulo: Atlas, 2009.

GOMES FILHO, A. S.; MEDEIROS, J. L.; MELO, M. A. S.; TORRES, C. M. G.; SANTOS, C. E.. "Meninas para um lado, meninos para o outro": questões de gênero e sexualidade na escola. In: ENCONTRO DE PÓS-GRADUAÇÃO E PESQUISA DA UNIVERSIDADE DE FORTALEZA-UNIFOR, 15. Anais. 2015.

GOMES FILHO, A. S.. Corpo, sexo, gênero e biopolítica. In: MELO, M. A. S.; GOMES FILHO, A. S. QUEIROZ, Z. F.. Epistemologias em confronto no Direito: reinvenções, ressiginificações e representações a partir da interdisciplinaridade. Curitiba: CRV, 2017a.

GOMES FILHO, A. S.. Relações de trabalho e transformações das famílias: uma perspectiva sócio-histórica. In: MELO, M.
A. S.; GOMES FILHO, A. S. QUEIROZ, Z. F.. Epistemologias em confronto no Direito: reinvenções, ressiginificações e representações a partir da interdisciplinaridade. Curitiba: CRV, 2017b.

GOMES FILHO, A. S.; SANTOS, C. E.; SILVA, L. M.. Sexo, Gênero, Sexualidade: Via(da)gens em Conceitos. Id on Line Revista Multidisciplinar e de Psicologia, v.10, n.33, p.20-36, 2017a.

HOHENDORFF, J. V.. Como escrever um artigo de revisão sistemática. In: KOLLER, S. H.; COUTO, M. C. P. P.; HOHENDORFF, J. V.. Manual de produção científica. Porto Alegre: Penso, 2014.

JALÓN, M. J. D-A. Sexismo, violencia de género y acoso escolar. Propuestas para una prevención integral de la violência. Revista de Estudios de Juventud, n.73, 2006.

JUNQUEIRA, R. D.. Introdução: Homofobia nas Escolas: um problema de todos. In: JUNQUEIRA, R. D.. Diversidade Sexual na Educação: problematizações sobre a homofobia nas escolas. Brasília: Ministério da Educação, Secretaria de Educação Continuada, Alfabetização e Diversidade, UNESCO, 2009.

LOURO, G. L.. Gênero, sexualidade e educação: uma perspectiva pós-estruturalista. 6 ed. Petrópolis: Vozes, 2003.

LOURO, G. L.. Pedagogias da Sexualidade. In: LOURO, G. L.. 0 corpo educado: pedagogias da sexualidade. 2 ed. Belo Horizonte: Autêntica, 2000.

MARCONI, M. A.; LAKATOS, E. M.. Fundamentos de metodologia científica. 8 ed. São Paulo: Atlas, 2017.

MOREIRA, A. F.; TADEU, T.. Sociologia e teoria crítica do currículo: uma introdução. In: MOREIRA, A. F.; TADEU, T.. Currículo, cultura e sociedade. 12 ed. São Paulo: Cortez, 2013.

Ó, J. R.. Para uma genealogia do currículo: ordem e método na edificação do modelo escolar moderno. In: CAVALCANTE, M. J. M.; HOLANDA, P. H. C.; LUSTOSA, F. G.; DIAS, R. B.. Histórias de Pedagogia, Ciências e Religião: discursos e correntes de cá e do além-mar. Fortaleza: UFC, 2016.

QUARESMA, L.. Violência escolar e de género: vivências e representações sociais discentes. Revista do Departamento de Sociologia da Faculdade de Letras da Universidade do Porto, v.20, 2010.

QUIRINO, G. S.. Humanização, ética, responsabilidade socia e direitos humanos nas práticas de cuidado em saúde. In: MELO, M. A. S.; GOMES FILHO, A. S. QUEIROZ, Z. F..

Epistemologias em confronto no Direito: reinvenções, ressiginificações e representações a partir da interdisciplinaridade. Curitiba: CRV, 2017.

SANTOMÉ, J. T.. Globalização e interdisciplinaridade: o currículo integrado. Porto Alegre: Artes Médicas, 1998.

TURNER, J. H.. Sociologia: conceitos e aplicações. São Paulo: MAKRON Books, 1999. 
VILLELA, W.; MONTEIRO, S.; VARGAS, E.. A incorporação de novos temas e saberes nos estudos em saúde coletiva: o caso do uso da categoria gênero. Ciênc. Saúde Coletiva, v.14, n.4, p.997-1006, 2009. DOI: http://doi.org/10.1590/S1413-81232009000400002
WEEKS, J.. O corpo e a sexualidade. In: LOURO, G. L.. O corpo educado: pedagogias da sexualidade. 2 ed. Belo Horizonte: Autêntica, 2000.

A CBPC - Companhia Brasileira de Produção Científica (CNPJ: 11.221.422/0001-03) detém os direitos materiais desta publicação. Os direitos referem-se à publicação do trabalho em qualquer parte do mundo, incluindo os direitos às renovações, expansões e disseminações da contribuição, bem como outros direitos subsidiários. Todos os trabalhos publicados eletronicamente poderão posteriormente ser publicados em coletâneas impressas sob coordenação da Sustenere Publishing, da Companhia Brasileira de Produção Científica e seus parceiros autorizados. Os (as) autores (as) preservam os direitos autorais, mas não têm permissão para a publicação da contribuição em outro meio, impresso ou digital, em português ou em tradução. 